\title{
Neuro-behavioral pattern of sleep bruxism in wakefulness
}

\author{
Marila Rezende Azevedo ${ }^{1 *}$, Ronaldo Sena ${ }^{1}$, Amanda Medeiros de Freitas ${ }^{1}$, Andrei Nakagawa Silva ${ }^{1}$, \\ Edgard Afonso Lamounier Júnior ${ }^{1}$, Alcimar Barbosa Soares ${ }^{1}$ \\ ${ }^{\prime}$ Biomedical Engineering Lab, Faculty of Electrical Engineering, Federal University of Uberlândia, Uberlândia, MG, Brazil.
}

\begin{abstract}
Introduction: Sleep Bruxism (SB) is a non-functional rhythmic movement of the mandible with multifactorial aetiology and complex diagnose. It has been the subject of various studies over the past decades and it is considered a result of actions of the Central Nervous System modulated by Autonomous Nervous System. In this work, we test the hypothesis that SB subjects present a typical and defined neurobehavioral pattern that can be distinct from that of non-bruxers subjects and can be measured during wakefulness. Methods: Fifteen sleep bruxers (experimental-group EG) and fifteen non-bruxers (control-group CG) took part in the experiments. To verify the presence and severity of SB, clinical examinations, anamneses and questionnaires, including Visual Analogic Scale - faces (VAS-f) and State-Trait Anxiety Inventory (STAI) were applied. To legitimate the diagnoses of SB, a disposable instrument $\left(\right.$ Bitestrip $\left.^{\circledR}\right)$ to assess the masseter activity during sleep was employed. All subjects were submitted to a set of experiments for measuring various visual evoked responses during the presentation of visual stimuli (pleasant, unpleasant and neutral images). Events in Visual Evoked Potential (VEP) were used to compare the neural responses of both CG and EG. Results: VAS-f showed EG with higher perception of stress than CG (trait: $\mathrm{p}=0.05$ ), and lower quality of life for (state: $\mathrm{p}=0.007$ ). STAI I and II showed significant differences of anxiety between $\mathrm{CG}$ and $\mathrm{EG}$ ( $\mathrm{p}=0.013$ and $\mathrm{p}=0.004$, respectively), being $\mathrm{EG}$ the highest. The EG Bitestrip scores confirmed that $100 \%$ of subjects were sleep bruxers. Significant differences were found between EG and CG for events associated with emotional (pleasant and unpleasant) images in the first $250 \mathrm{~ms}$ after stimulation. In general, EG subjects showed higher amplitude and shorter latency of VEP events. Conclusion: It is possible to distinguish between SB and non-bruxers subjects during wakefulness, based on differences in amplitude and latency of cortical event related potentials elicited by visual stimulation. SB subjects show greater amplitudes in specific events in frontal areas when non-pleasant images are shown. Latencies tend to be anticipated in SB compared to CG subjects.
\end{abstract}

Keywords Sleep bruxism, Emotion, EEG, Visual evoked potential, Anxiety, Wakefulness.

\section{Introduction}

Sleep Bruxism (SB) is a complex phenomenon considered to be primarily a sleep-related movement disorder with a multifactorial aetiology, involving intricate multisystem physiological processes. It is no longer considered a parasomnia and its aetiology is not believed to be based on purely mechanical factors or psychological issues (Klasser et al., 2015). It has been observed that bruxism has a relevant role as a relief mechanism for psychosomatic disorders induced by

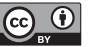

This is an Open Access article distributed under the terms of the Creative Commons Attribution License, which permits unrestricted use, distribution, and reproduction in any medium, provided the original work is properly cited.

How to cite this article: Azevedo MR, Sena R, Freitas AM, Silva AN, Lamounier Júnior EA, Soares AB. Neurobehavioral pattern of sleep bruxism in wakefulness. Res Biomed Eng. 2018; 34(1):1-8. DOI: $10.1590 / 2446-4740.06617$

*Corresponding author: Biomedical Engineering Lab, Faculty of Electrical Engineering, Federal University of Uberlândia, Campus Sta Mônica, Av. João Naves de Ávila, 2121, Bloco 1E, CEP 38400-000, Uberlândia, MG, Brazil. E-mail: marila.azevedo@terra.com.br Received: 04 December 2017/ Accepted: 27 December 2017 stress (Sato et al., 2008). SB is present in childhood and may persist into adulthood (Kato et al., 2012). It occurs after abrupt changes in physiological rhythms including cortical hyperactivity, fast breathing, fast cardiac activity and muscle hyperactivity with final dental contact (Dubé et al., 2004; Lavigne et al., 2007). When this phenomenon was registered and identified by polysomnography in various studies, a major shift in the understanding of sleep bruxism took place (Dubé et al., 2004; Huynh et al., 2007). The most recent hypotheses on the aetiology of SB supports the roles of the central (CNS) and autonomous (ANS) nervous systems in the genesis of the oromandibular activity during sleep, which happens when a stressor agent (emotion, fear, anger or pain) is present and alters the activity of the ANS, exacerbating the sympathetic activity as a response (Sato et al., 2008; Sato and Slavicek, 2008). Those hypotheses are supported by the so-called, cardio-trigeminal reflex theory, which states that when there is emotional suffering, stress is generated leading to the activation of motoneurons, which triggers muscle tension (Barreto and Silva, 2010; Lobbezoo, 2016). This resulting dental pressure triggers 
the trigeminal nervous system that spreads electrical signals to its nucleus in the brain stem, inducing the activity of the parasympathetic system, which in turn decreases the state of cardiac, respiratory and muscular excitation. That is why SB is also considered as part of a stress relief system in subjects high stressed or anxious (Schames et al., 2012).

SB is a disorder of high prevalence, especially in the most productive adult phase. Compared to awake bruxism, SB is considered to cause greater damage, as it generates unconscious movement and co-contraction forces about $30 \%$ stronger than those at maximum voluntary contraction (Behr et al., 2012).

Several authors have claimed that sleep bruxers have a typical behavioral profile that differs from non-bruxers, being more prone to anxiety and prompt to react (Bayar et al., 2012; Lobbezoo et al., 2013). Ahlberg et al. (2013) suggest that underlying anxiety and stress may exacerbate bruxism, and also cause more frequent arousals during sleep. Finally, Hajcak et al. (2010), in a major review on event-related potentials and emotion regulation, described a number of studies that strongly correlated specific cortical responses with emotion regulation. Since SB subjects tend to be highly stressed and anxious individuals, those finds lead to hypothesize that it may be possible that the different behavioral profiles of sleep bruxers and non-bruxers may be revealed during the evaluation of cortical responses to stressful stimuli during wakefulness.

In the light of such arguments, we propose a novel method to discriminate subjects with and without SB by assessing the cortical responses to various visual stimuli during vigilance. In so doing, we hope to contribute towards the comprehension of the peculiar behavioral expression of SB subjects and to the establishment of a proven scientific diagnostic criterion for sleep bruxism.

\section{Methods}

Thirty healthy subjects (20-33 years old) participated in the experiment. The experimental procedures were explained in detail to each subject, who also signed an informed consent form (Ethics Committee Protocol CEP/UFU/650.649). All subjects presented complete dentition (except for orthodontic or third molars extractions), reported no use of antidepressants or anxiolytic drugs and were not in orthodontic treatment. In order to assess if they would be categorized as sleep bruxers or non-bruxers, the volunteers underwent clinical examination by a senior dentist. Oral and extra-oral examinations, Modified Fonseca's Anamneses, Research Diagnostic Criteria Index (RDC I and II), and Oral Health Impact Profile 14 (OHIP Br 14) were applied to identify symptoms of bruxism, temporomandibular disorder, dental history and oral habits. All subjects also responded anxiety questionnaires (Néri's Life Satisfaction Questionnaire; State-Trait Anxiety Inventory - STAI I and STAI II; Visual Analog Scale-faces Trait - VAS-f T and Quality of Life - VAS-f QL) to recognize how they perceive their daily lives and their current situation. Furthermore, the EMG activity of masseter muscles was measured during sleep, using the BiteStrip ${ }^{\circledR}$ device (Up2dent Inc, Germany) (Shochat et al., 2007; Mainieri et al., 2012). Those who were diagnosed with SB were assigned to the experimental group $(E G, n=15)$ and the others to the control group ( $\mathrm{CG}, \mathrm{n}=15)$.

All volunteers were submitted to a set of experiments for measuring various visual evoked responses during the presentation of visual stimuli (static images displayed on a monitor). For measuring the cortical visual evoked responses (or Visual Evoked Potentials - VEP), electroencephalographic (EEG) signals were acquired via an EEG data acquisition system $\left(\right.$ EBNeuro $^{\circledR}$, Firenze - Itália, 16-bit A/D resolution, $1024 \mathrm{~Hz}$ sampling rate). Nineteen individual electrodes were placed on the scalp, in accordance with the international 10/20 system (Fp1, Fp2, F7, F3, Fz, F4, F8, T3, C3, Cz, C4, T4, T5, P3, $\mathrm{Pz}, \mathrm{P} 4, \mathrm{~T} 6, \mathrm{O} 1$ and $\mathrm{O} 2$ ), two reference electrodes were placed on both auricles and one on the mastoid area as ground reference.

To elicit the evoked potentials, a sample of 60 color images were selected from The International Affective Picture System (IAPS) database (Lang et al., 2005). IAPS images are also classified by their valences as 'negative', 'neutral' and 'positive', according to the emotions they arouse in the individual. 20 images were randomly chosen from the databank for each of the three levels of valences to compose the set of 60 images, which were randomly displayed on a monitor positioned in front of the subjects while the EEG data was acquired. An auxiliary signal was also acquired to allow for the synchronization of the presentation of each image, as well as its valence level. Figure 1 illustrates the process used to present the images during the experiment. First a blank screen was presented for $2250 \mathrm{~ms}$ (relaxation phase), followed by a fixation cross on the center of the screen displayed during $750 \mathrm{~ms}$; next, the image was displayed during $500 \mathrm{~ms}$. This procedure, adapted from Capela and Georgieva (2012), continued until all 60 images were shown to the volunteer. Figure 2 shows the setup used for acquiring the visual evoked responses.

\section{Artifact removal}

Prior to any processing, all EEG signals were filtered by means of $60 / 120 \mathrm{~Hz}$ notch filters (Butterworth, 5 poles) and a $0.1-30 \mathrm{~Hz}$ bandpass filter (Butterworth, 4 poles), in order to reduce power line interference and DC artifacts. 


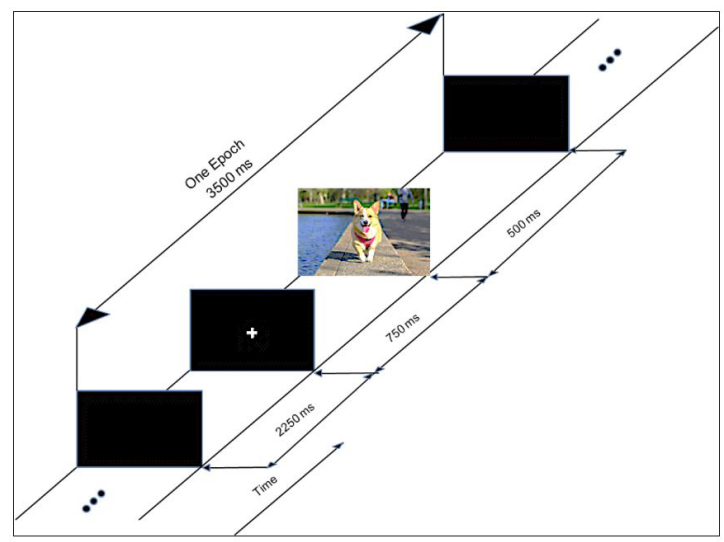

Figure 1. Steps and timeline used to present the set of images during the VEP experiment.

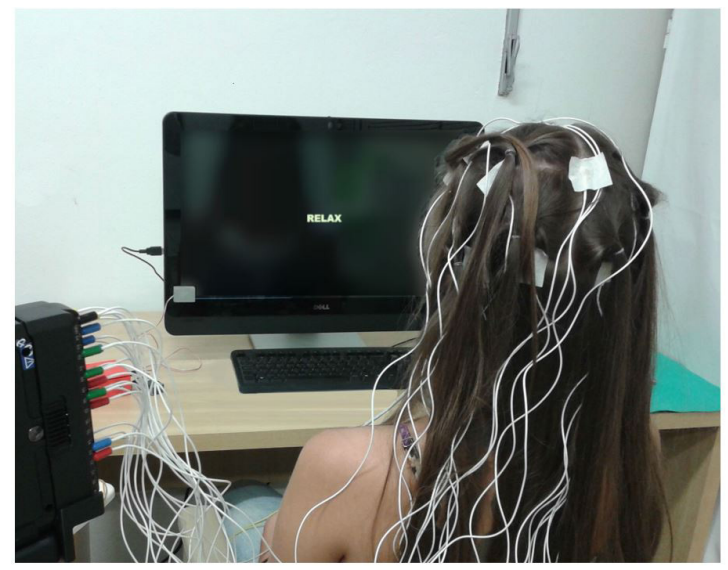

Figure 2. The experimental setup used for the VEP experiments. The volunteers sat comfortably in a chair while a set of images were presented on a computer screen placed at a distance of $70 \mathrm{~cm}$. EEG data were collected throughout the experiment along with a synchronization signal used to indicate the presentation and valence of each image.

In addition, Independent Component Analysis (ICA) was used to remove ocular artifacts. To identify the independent component (IC) for the blinking signal, the correlation coefficient between each IC and the cortical signals measured on the Fp1 and Fp2 channels were calculated. The IC with the highest correlation coefficient was eliminated from all EEG channels (Jung et al., 2000; Gómez-Herrero et al., 2006). Once the IC was eliminated, a threshold of $40 \mu \mathrm{V}$ was established and the EEG epochs that exceeded this value were excluded. Furthermore, the trials were visually inspected to ensure that no residual artifacts would affect the analyses.

\section{Epoch extraction}

The epochs were extracted from all channels from $100 \mathrm{~ms}$ before the stimulus-onset (image presentation) to $1000 \mathrm{~ms}$ after the stimulus-onset. After extraction, all epochs were referred to the mean amplitude of the pre-stimulus baseline (Guo et al., 2015).

\section{Feature extraction}

The grand averages for all EEG channels and all subjects were calculated for each type of valence (negative, neutral and positive). Thus, 57 grand averages were calculated for each subject (3 valences x 19 channels). Next, amplitude $(\mu \mathrm{V})$ and latency (ms) were measured, for each one of those grand averages, for the following events: N100 and P100 (50-150ms); N200 and P200 (150-250 ms); N300 and P300 (250-350 ms). The choice of events and the different intervals were based on related literature (Olofsson et al., 2008). To detect the onset of the events in each grand average, a search for the global maxima and minima (if P100/200/300 or N100/200/300) was performed at the pre-defined intervals. Furthermore, after the automatic process was executed, the onsets were inspected to make sure they were correct. Once the onsets were considered satisfactory, their latency and amplitude were stored for the further processing.

\section{Statistical analysis}

\section{Clinical evaluation}

To evaluate the correlation between bruxism and the various parameters measured during the anamneses and clinical evaluations, the Phi Coefficient (a variation of the Pearson correlation and measures the relationship of binary data, related to the chi-square statistic) and the p-value (correlation of nominal data) were used (Witz et al., 1990; Brown and Donovan, 2014).

\section{Evaluation of cortical evoked responses}

To evaluate the statistical differences between the evoked responses of the two groups of volunteers (CG x EG), the events in the grand averages of each valence and channel were compared (Pfurtscheller and Lopes da Silva, 1999). The normality of the data set was first calculated and then a paired t-test (normal) or Wilcoxon signed-rank test (non-normal) was applied to evaluate the statistical significance of differences between the features extracted (latency and amplitude of the events).

\section{Results}

\section{Clinical evaluation}

Evaluations of anamneses and clinical data were performed to find out which elements were related to bruxism. Considering the various elements of the anamneses and the questionnaires that were applied to both groups, the statistical analysis showed that only STAI and VAS were significant when testing possible 
differences between EG and CG: STAI I $(p=0.013)$, STAI II $(p=0.003)$, VAS-f T $(p=0.05)$ and VAS-f QL $(\mathrm{p}=0.007)$.

The Bitestrip device was used to count the episodes of bruxism during sleep, thus measuring the presence and severity of BS. The device was designed to screen masseter EMG events and discriminate normal activity from SB events (Mainieri et al., 2012). Bitestrip scores can be used to discriminate four possible outcomes: L - no event; 1 - mild; 2 - moderate; 3 - severe. Our results showed that SB subjects (EG) graded from 2 (moderate) to 3 (severe), while non-bruxers (CG) graded L or 1 . These findings are consistent with the literature (Mainieri et al., 2012) and provide further support for the clinical evaluations performed to discriminate between sleep bruxers and non-bruxers.

\section{Visual evoked responses}

57 grand averages (3 valences x 19 EEG channels) were calculated for each subject and the latencies and amplitudes of the relevant events (N100, P100, N200, P200, N300 and P300) were measured. Figure 3 shows an example of grand averages calculated for channel $\mathrm{C} 3$ when neutral images were shown to control $(\mathrm{CG})$ and experimental (EG) subjects.

To test the differences in amplitude and latency for the various events occurring during the presentation of images, the normality of the data (events across all volunteers/channels/valences) was first tested. Since the results showed a normal distribution, the paired t-test was used to look for differences in the amplitude and latency of the events found between $\mathrm{CG}$ and $\mathrm{EG}$.

Tables 1 and 2 show the amplitude and latency of the events, along with the related EEG channel and valence, that were statistically different between $\mathrm{CG}$ and $\mathrm{EG}(\mathrm{p}<0.05)$.

Of all channels, only FP1, FP2, F4 and F7 showed statistically significant differences within groups when the amplitude of the events for the different valences and channels were compared. Notice that, except for P200 in F7 (for images with positive valence), the amplitude of all events in the EG group was consistently higher (absolute value) for the experimental group. Besides, negative images show a much stronger effect on the differences of amplitude.

As shown in Table 2, differences in latency were observed only in channels $\mathrm{P} 3, \mathrm{C} 3, \mathrm{~T} 6, \mathrm{~T} 5, \mathrm{O} 2$ and $\mathrm{P} 3$. Except for channel P3, all channels showed an early manifestation of the events in the EG group in relation to $\mathrm{CG}$.

Table 1. Statistically significant correlations for the differences in amplitude of the VEP components, regarding channel sources and image valences in both groups.

\begin{tabular}{cccccc}
\hline $\begin{array}{c}\text { EEG } \\
\text { channel }\end{array}$ & Valence & Event & p-value & $\begin{array}{c}\text { Amplitude } \\
\mathbf{C G}(\boldsymbol{\mu V})\end{array}$ & $\begin{array}{c}\text { Amplitude } \\
\mathbf{E G}(\boldsymbol{\mu V})\end{array}$ \\
\hline FP1 & Negative & N100 & 0.0024 & -1.02 & -2.36 \\
FP2 & Negative & N100 & 0.0099 & -0.46 & -2.39 \\
F4 & Negative & N100 & 0.0312 & -0.51 & -1.18 \\
F7 & Positive & P100 & 0.0381 & 0.84 & 0.98 \\
F7 & Positive & P200 & 0.0142 & 0.32 & 0.22 \\
\hline
\end{tabular}

EG: experimental; CG: control.

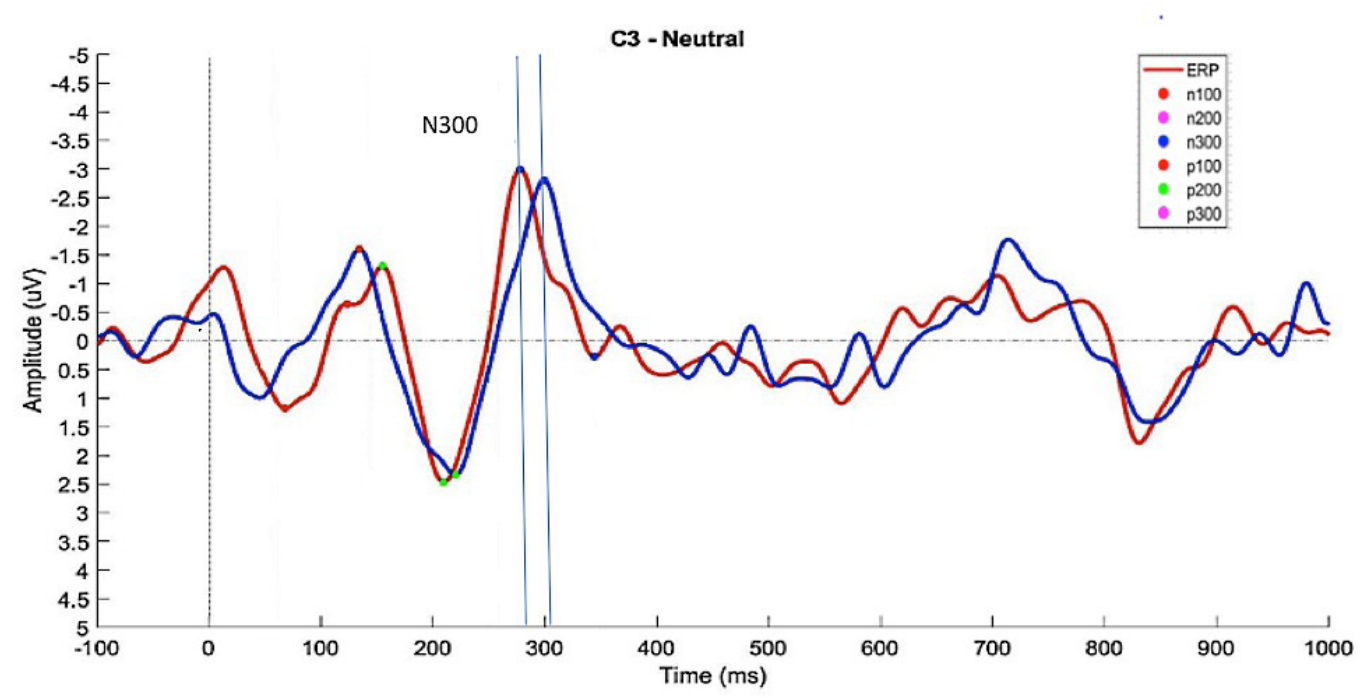

Figure 3. CG (blue) and EG (red) grand averages of 'Neutral' epochs for C3. The vertical dashed line indicates the stimulus onset (image presentation $=0 \mathrm{~ms}$ ); Colored dots on the waveforms show the events detected (note that, for this specific example, a P300 event was not detected for the CG group within the pre-defined interval (250-350 ms). 
Table 2. Statistically significant correlations for the differences in latency of the VEP components, regarding channel sources and image valences in both groups.

\begin{tabular}{cccccc}
\hline EEG channel & Valence & Event & p-value & Latency CG $(\mathbf{m s})$ & Latency EG $(\mathbf{m s})$ \\
\hline P3 & Negative & P200 & 0.0360 & 209.57 & 218.36 \\
T6 & Negative & N100 & 0.0340 & 83.59 & 67.97 \\
T6 & Negative & P300 & 0.0001 & 344.34 & 268.16 \\
C3 & Neutral & N300 & 0.0268 & 299.41 & 277.93 \\
T5 & Neutral & P200 & 0.0136 & 230.08 & 209.57 \\
O2 & Neutral & N300 & 0.0040 & 297.46 & 275.98 \\
Fp1 & Positive & P300 & 0.0336 & 347.27 & 292.58 \\
\hline
\end{tabular}

EG: experimental; CG: control.

\section{Discussion}

In this research, the evaluation of the cortical activity of sleep bruxers and non-bruxers during wakefulness revealed distinct neurobehavioral patterns. Compared to CG subjects, SBs showed VEP components of higher amplitude and earlier manifestation (latency) when subjected to visualization of affective images of different valences.

Besides cortical activity, we also investigated various clinical aspects by means of questionnaires, anamneses, scales, inventories and clinical examinations. Among all signs and symptoms investigated, the State-Trait Anxiety Inventory (STAI) and the Visual Analogic Scale - faces (VAS-f) were the indexes that showed the highest correlation with SB. In fact, those indexes are commonly used for assessing how each individual cope with stress and anxiety (STAI being the gold standard to diagnose anxiety) (Kaipper, 2008). Our results showed an outstanding statistical significance associating daily anxiety with sleep bruxers. With regard to the masseter activity during sleep, the Bitestrip measurements confirmed that EG individuals (sleep-bruxers) had also the highest ranges of non-normal EMG activity when sleeping.

The literature considers that perfectionist individuals, with distinct threshold of tolerance, repressed aggression, anxiety, frustration and depression, among other emotional characteristics, may have increased cortical activity when submitted to intense emotions (Seger, 1998). SB subjects have been cited as individuals with typical behavioral and mood profiles (Ahlberg et al., 2013; Mayer et al., 2016), with greater difficulty to adapt to new situations, and are usually goal-oriented, sensitive, anxious and stressed (Mayer et al., 2016). For many individuals, such intense emotional and even physical responses may persist until bedtime (Manfredini et al., 2011). This psychobiological state of hyper excitation may contribute to give raise, during the night, to repetitive masticatory muscle activity (RMMA) in SB subjects (Riemann et al., 2010). Also, highly interoceptive individuals tend to be more perceptive to internal, visceral, and affective events (Herbert et al., 2007). Furthermore, emotional changes related to stress and emotions have been identified in the cerebral cortex and subcortical regions by means of event related potentials (ERPs) (Polich, 2007; Capela and Georgieva, 2012). In our study, the cortical responses of the experimental group seem to be in line with those findings, since the SB subjects also showed a significant level of anxiety and stress.

When analyzing Tables 1 and 2, one can observe a tendency of higher cortical activity (amplitude) in the neural substrate of EG individuals for VEP components around $100 \mathrm{~ms}$ (N100 for negative images, and P100 and P200 for positive images) in channels FP1, Fp2, F4 and F7. When the differences in latency were investigated, the results also showed that $C G$ individuals had a later initiation of VEP components in relation to the response of EG subjects, indicating that the EG subjects tend to react to stimuli faster than CG subjects. The latency of the P200 and N300 events occurred more frequently for neutral figures than for unpleasant and pleasant figures, and were anticipated in EG compared to CG. This behavior of later latency is presumably related to higher processing stages (Amrhein et al., 2004).

N100 has been regarded as a rapid neural response associated with the detection of unpleasant visual phenomena, with an important role in bringing our brain to a state of alertness (Keil et al., 2002; Schupp et al., 2003; Foti et al., 2009). Nevertheless, the tendency to over process threat-related information has been identified as a major cause of anxiety disorders (Mathews and MacLeod, 2002; Bar-Haim et al., 2007). In our research, N100 was found to be highly associated with emotional images, both for amplitude and latency, with negative images generating greater neural activity in the EG than CG. The origin of this fast response is thought to start in the prefrontal cortex (Kawasaki et al., 2001; Carretié et al., 2004) when negative stimulus is briefly presented or even perceived unconsciously (Carretié et al., 2006). Anatomical studies on ventromedial prefrontal cortex connections show that this area sends projections to executor structures, such as the amygdala and pre-motor cortex, responsible for motor and autonomic responses to aversive events (Codispoti et al., 2006) and to the 
posterior areas of the brain involved in visual attention and object recognition (Sarter et al., 2001; Armony and Dolan, 2002). Evidence suggests that N100 does not originate in the primary visual cortex, but rather in several generators in the frontal and occipito-temporal-parietal regions (Clark et al., 1994), as observed also in this study. This rapid response to negative stimulus may be related to a neural adaptation mechanism, which helps survival by facilitating fast coping with aversive or dangerous events (Cacioppo and Gardner, 1999; Taylor et al., 2006). Similarly, the P100 component, which occurred in F7 with amplitudes higher in the EG than in CG, is considered a sensitive component to physical stimuli and indicates early processes in prefrontal, frontal and striated visual cortex.

Studies on the origins of P100, P200 and N200, suggest that, as soon as the sequence progresses from P100 to N200, the anterior cingulate cortex (ACC) is increasingly involved, with activation moving from dorsal to ventral ACC (Carretié et al., 2004). However, in our research, the N200 component did not show statistical significance for any of the selected channels, neither for latency nor amplitude. On the other hand, P200 has been hypothesized to be part of longer neural processing associated with the manifestation of a cognitive system located around the parieto-occipital and central-frontal regions, which compares sensory inputs with stored memory (Freunberger et al., 2007). This corroborates our findings for the latency of P200 - occurring in channel P3 during the presentation of negative emotional images; being longer for EG than for CG. P200 also showed statistical significance for differences in amplitude between EG and CG on frontal substrate (channel F7).

P300 and N300 only showed statistically significant differences in the latency of the events between EG and CG for channels T6, C3, O2 and Fp1.

N300 has been recognized as a component particularly sensitive to visual stimuli generated by emotional images (Rossignol et al., 2005). With regard to the latency of the N300, subjects with anxiety, fears or phobias showed faster reaction time than control group subjects in the experiments performed by Flykt and Caldara (2006) and Michalowski et al. (2009). In our study, EG subjects, who also had higher levels of anxiety compared to CG subjects, showed faster reaction times (shorter latencies) in channels $\mathrm{C} 3$ and $\mathrm{O} 2$.

P300 has also been shown to be sensitive to the emotional contents of visual images in highly anxious individuals (Schupp et al., 2004; Weinberg and Hajcak, 2010). Those findings are also correlated with our results, were emotional images, with negative and positive valences, showed significant statistical differences between EG and CG for the latencies of P300 in channels T6 (negative) and Fp1 (positive).
In our experiments, most of the differences found in events associated with emotional (pleasant and unpleasant) images occurred in the first $250 \mathrm{~ms}$ after stimulation, as also perceived in the work of Codispoti et al. (2006). Similar results were also found by other researchers, when studying the influence of anxiety and stress in the cortical responses of different subjects (Foti et al., 2009; Hajcak et al., 2010).

ERPs associated with emotional processing have also been used to examine the hypothesis that negative information may hold a more privileged status (importance of an event, memory or previous experience) among emotional contents. It was found that, negative information evokes stronger physiological and emotional reactions in comparison to neutral and positive information (Cacioppo and Gardner, 1999). This has also been highlighted in our results. In fact, the occurrence of negative valence prevailed over positive and neutral valences. Furthermore, the dominance occurred mostly for events within the first $250 \mathrm{~ms}$ (P100, N100 and P200).

Overall, our findings suggest that it is possible to distinguish between SB and non-bruxers subjects during wakefulness, based on differences in the amplitude and latency of cortical event related potentials elicited by visual stimulation using emotional and non-emotional images. SB subjects show greater amplitudes in specific events in the frontal areas when non-pleasant images are shown, when compared to non-bruxers. Latencies tend to be anticipated in SB compared to CG subjects. Those results, along with the information gathered by clinical examination and specific questionnaires, allow us to conclude that SB individuals show a distinct behavioral pattern that influences cortical activity, persists during the day, and can be detected by means of VEPs.

\section{Acknowledgements}

The authors would like to thank CAPES, CNPq and FAPEMIG, Brazil, for the financial support.

\section{References}

Ahlberg J, Lobbezoo F, Ahlberg K, Manfredini D, Hublin C, Sinisalo J, Könönen M, Savolainen A. Self-reported bruxism mirrors anxiety and stress in adults. Med Oral Patol Oral Cir Bucal. 2013; 18(1):e7-11. PMid:22926484. http://dx.doi. org/10.4317/medoral.18232.

Amrhein C, Muhlberger A, Pauli P, Wiedemann G. Modulation of event-related brain potentials during affective picture processing: a complement to startle reflex and skin conductance response? Int J Psychophysiol. 2004; 54(3):231-40. PMid:15331214. http://dx.doi.org/10.1016/j.ijpsycho.2004.05.009.

Armony J, Dolan R. Modulation of spatial attention by fear-conditioned stimuli: an event-related fMRI study. 
Neuropsychologia. 2002; 40(7):817-26. PMid:11900732. http:// dx.doi.org/10.1016/S0028-3932(01)00178-6.

Bar-Haim Y, Lamy D, Pergamin L, Bakermans-Kranenburg MJ, van Ijzendoorn MH. Threat-related attentional bias in anxious and nonanxious individuals: a meta-analytic study. Psychol Bull. 2007; 133(1):1-24. PMid:17201568. http:// dx.doi.org/10.1037/0033-2909.133.1.1.

Barreto JEF, Silva LP. Sistema límbico e as emoções: uma revisão anatômica. Rev Neurocienc. 2010; 18(3):386-94.

Bayar GR, Tutuncu R, Acikel C. Psychopathological profile of patients with different forms of bruxism. Clin Oral Investig. 2012; 16(1):305-11. PMid:21221680. http://dx.doi.org/10.1007/ s00784-010-0492-9.

Behr M, Hahnel S, Faltermeier A, Bürgers R, Kolbeck C, Handel G, Proff P. The two main theories on dental bruxism. Ann Anat. 2012; 194(2):216-9. PMid:22035706. http://dx.doi. org/10.1016/j.aanat.2011.09.002.

Brown G, Donovan S. Measuring change in place values for environmental and natural resource planning using public participation GIS (PPGIS): results and challenges for longitudinal research. Soc Nat Resour. 2014; 27(1):36-54. http://dx.doi.or g/10.1080/08941920.2013.840023.

Cacioppo JT, Gardner WL. Emotion. Annu Rev Psychol. 1999; 50(1):191-214. PMid:10074678. http://dx.doi.org/10.1146/ annurev.psych.50.1.191.

Capela NF, Georgieva P. Aplicação de técnicas de aprendizagem automática para classificação de emoções humanas com sinais de EEG. Electrónica e Telecomunicações. 2012; 5(4):391-9.

Carretié L, Hinojosa JA, Albert J, Mercado F. The neural response to sustained affective visual stimulation using an indirect task. Exp Brain Res. 2006; 174(4):630-7. PMid:16708242. http:// dx.doi.org/10.1007/s00221-006-0510-y.

Carretié L, Hinojosa JA, Martín-Loeches M, Mercado F, Tapia M. Automatic attention to emotional stimuli: neural correlates. Hum Brain Mapp. 2004; 22(4):290-9. PMid:15202107. http:// dx.doi.org/10.1002/hbm.20037.

Clark VP, Fan S, Hillyard SA. Identification of early visually evoked potential generators by retinotopic and topographic analyses. Hum Brain Mapp. 1994; 2(3):170-87. http://dx.doi. org/10.1002/hbm.460020306.

Codispoti M, Ferrari V, Bradley M. Repetitive picture processing: autonomic and cortical correlates. Brain Res. 2006; 1068(1):213-20. PMid:16403475. http://dx.doi.org/10.1016/j. brainres.2005.11.009.

Dubé C, Rompre PH, Manzini C, Guitard F, De Grandmont P, Lavigne GJ. Quantitative polygraphic controlled study on efficacy and safety of oral splint devices in tooth-grinding subjects. J Dent Res. 2004; 83(5):398-403. PMid:15111632. http://dx.doi.org/10.1177/154405910408300509.

Flykt A, Caldara R. Tracking fear in snake and spider fearful participants during visual search: a multi-response domain study. Cogn Emotion. 2006; 20(8):1075-91. http://dx.doi. org/10.1080/02699930500381405.

Foti D, Hajcak G, Dien J. Differentiating neural response to emotional pictures: evidence from temporal-spatial PCA.
Psychophysiology. 2009; 46(3):521-30. PMid:19496228. http:// dx.doi.org/10.1111/j.1469-8986.2009.00796.x.

Freunberger R, Klimesch W, Doppelmayr M, Höller Y. Visual $\mathrm{P} 2$ component is related to theta phase-locking. Neurosci Lett. 2007; 426(3):181-6. PMid:17904744. http://dx.doi.org/10.1016/j. neulet.2007.08.062.

Gómez-Herrero G, De Clercq W, Anwar H, Kara O, Egiazarian K, Huffel SV, Van Paesschen W. Automatic removal of ocular artefacts in the EEG without an EOG reference channel. In: Proceedings of the 7th Nordic Signal Processing Symposium (NORSIG 2006); 2006; Rejkjavik, Iceland. USA: IEEE; 2006.

Guo M, Xu G, Wang L, Masters M, Milsap G, Thakor N, Soares AB. The anterior contralateral response improves performance in a single trial auditory oddball BMI. Biomed Signal Process Control. 2015; 22:74-84. http://dx.doi. org/10.1016/j.bspc.2015.06.014.

Hajcak G, MacNamara A, Olvet DM. Event-related potentials, emotion, and emotion regulation: an integrative review. Dev Neuropsychol. 2010; 35(2):129-55. PMid:20390599. http:// dx.doi.org/10.1080/87565640903526504.

Herbert BM, Pollatos O, Schandry R. Interoceptive sensitivity and emotion processing: an EEG study. Int J Psychophysiol. 2007; 65(3):214-27. PMid:17543405. http://dx.doi.org/10.1016/j. ijpsycho.2007.04.007.

Huynh N, Manzini C, Rompré PH, Lavigne GJ. Weighing the potential effectiveness of various treatments for sleep bruxism. J Can Dent Assoc. 2007; 73(8):727-30. PMid:17949541.

Jung TP, Makeig S, Humphries C, Lee TW, Mckeown MJ, Iragui V, Sejnowski TJ. Removing electroencephalographic artefacts by blind source separation. Psychophysiology. 2000; 37(2):163-78. PMid:10731767. http://dx.doi.org/10.1111/14698986.3720163 .

Kaipper MB. Avaliação do inventário de ansiedade traço-estado (IDATE) através da análise de Rasch [dissertation]. Porto Alegre: Universidade Federal do Rio Grande do Sul; 2008.

Kato T, Velly AM, Nakane T, Masuda Y, Maki S. Age is associated with self-reported sleep bruxism, independently of tooth loss. Sleep Breath. 2012; 16(4):1159-65. PMid:22146891. http://dx.doi.org/10.1007/s11325-011-0625-7.

Kawasaki H, Kaufman O, Damasio H, Damasio AR, Granner M, Bakken H, Hori T, Howard MA 3rd, Adolphs R. Single neuron responses to emotional visual stimuli recorded in human ventral prefrontal cortex. Nat Neurosci. 2001; 4(1):15-6. PMid:11135639. http://dx.doi.org/10.1038/82850.

Keil A, Bradley MM, Hauk O, Rockstroh B, Elbert T, Lang P. Large-scale neural correlates of affective picture processing. Psychophysiology. 2002; 39(5):641-9. PMid:12236331. http:// dx.doi.org/10.1111/1469-8986.3950641.

Klasser GD, Rei N, Lavigne GJ. Sleep bruxism etiology: the evolution of a changing paradigm. J Can Dent Assoc. 2015; 81:f2. PMid:25633110.

Lang PJ, Bradley MM, Cuthbert BN. International Affective Picture System (IAPS): affective ratings of pictures and instruction manual. Gainesville: University of Florida; 2005. Technical Report A-6. 
Lavigne GJ, Huynh N, Kato T, Okura K, Adachi K, Yao D, Sessle B. Genesis of sleep bruxism: motor and autonomic-cardiac interactions. Arch Oral Biol. 2007; 52(4):381-4. PMid:17313939. http://dx.doi.org/10.1016/j.archoralbio.2006.11.017.

Lobbezoo F, Ahlberg J, Glaros AG, Kato T, Koyano K, Lavigne GJ, de Leeuw R, Manfredini D, Svensson P, Winocur E. Bruxism defined and graded an international consensus. J Oral Rehabil. 2013; 40(1):2-4. PMid:23121262. http://dx.doi. org/10.1111/joor.12011.

Lobbezoo F. Bruxism: definition, diagnosis, epidemiology, and etiology. In: Proceedings of the II Congresso Nazionale GSID (Gruppo di Studio Italiano Disordini Craniomandibolari); 2016 July 3-4; Marina di Carrara, Italy. Italy: GSID; 2016. p. 1-5.

Mainieri VC, Saueressig AC, Pattussi MP, Fagondes SC, Grossi ML. Validation of the Bitestrip versus polysomnography in the diagnosis of patients with a clinical history of sleep bruxism. Oral Surg Oral Med Oral Pathol Oral Radiol. 2012; 113(5):612-7. PMid:22668619. http://dx.doi.org/10.1016/j. oooo.2011.10.008.

Manfredini D, Fabbri A, Peretta R, Guarda-Nardini L, Lobbezoo F. Influence of psychological symptoms on home-recorded sleep-time masticatory muscle activity in healthy subjects. J Oral Rehabil. 2011; 38(12):902-11. PMid:21569074. http:// dx.doi.org/10.1111/j.1365-2842.2011.02226.x.

Mathews A, MacLeod C. Induced processing biases have causal effects on anxiety. Cogn Emotion. 2002; 16(3):331-54. http:// dx.doi.org/10.1080/02699930143000518.

Mayer P, Heinzer R, Lavigne G. Sleep bruxism in respiratory medicine practice. Chest. 2016; 149(1):262-71. PMid:26225899. http://dx.doi.org/10.1378/chest.15-0822.

Michalowski JM, Melzig CA, Weike AI, Stockburger J, Schupp HT, Hamm AO. Brain dynamics in spider-phobic individuals exposed to phobia-relevant and other emotional stimuli. Emotion. 2009; 9(3):306-15. PMid:19485608. http://dx.doi. org/10.1037/a0015550.

Olofsson JK, Nordin S, Sequeira H, Polich J. Affective picture processing: an integrative review of ERP findings. Biol Psychol. 2008; 77(3):247-65. P Sarter M, Givens B, Bruno JP. The cognitive Mid:18164800. http://dx.doi.org/10.1016/j. biopsycho.2007.11.006.

Polich J. Updating P300: an integrative theory of P3a and P3b. Clin Neurophysiol. 2007; 118(10):2128-48. PMid:17573239. http://dx.doi.org/10.1016/j.clinph.2007.04.019.

Pfurtscheller G, Lopes da Silva FH. Event-related EEG/MEG synchronization and desynchronization: basic principles. Clin Neurophysiol. 1999; 110(11):1842-57. PMid:10576479. http:// dx.doi.org/10.1016/S1388-2457(99)00141-8.

Riemann D, Spiegelhalder K, Feige B, Voderholzer U, Berger M, Perlis M, Nissen C. The hyperarousal model of insomnia: a review of the concept and its evidence. Sleep Med Rev. 2010;
14(1):19-31. PMid:19481481. http://dx.doi.org/10.1016/j. smrv.2009.04.002.

Rossignol M, Philippot P, Douilliez C, Crommelinck M, Campanella S. The perception of fearful and happy facial expression is modulated by anxiety: an event-related potential study. Neurosci Lett. 2005; 377(2):115-20. PMid:15740848. http://dx.doi.org/10.1016/j.neulet.2004.11.091.

Sarter M, Givens B, Bruno JP. The cognitive neuroscience of sustained attention: where top-down meets bottom up. Brain Res Rev. 2001; 35(2):146-60. PMid:11336780. http://dx.doi. org/10.1016/S0165-0173(01)00044-3.

Sato S, Sasaguri K, Ootsuka T, Saruta J, Miyake S, Okamura M, Sato C, Hori N, Kimoto K, Tsukinoki K, Watanabe K, Onozuka M. Bruxism and stress relief. In: Onozuka M, Yen CT, editors. Novel trends in brain science. Tokyo: Springer; 2008. p. 183-200. http://dx.doi.org/10.1007/978-4-431-73242-6_11.

Sato S, Slavicek R. The masticatory organ and stress management. Int J Stomatol Occlusion Med. 2008; 1(1):51-7. http://dx.doi. org/10.1007/s12548-008-0010-8.

Schames SE, Schames J, Schames M, Chagall-Gungur SS. Sleep bruxism, an autonomic self-regulating response by triggering the trigeminal cardiac reflex. J Calif Dent Assoc. 2012; 40(8):670-1, 674-6. PMid:22953526.

Schupp HT, Junghofer M, Weike AI, Hamm AO. Attention and emotion: an ERP analysis of facilitated emotional stimulus processing. Neuroreport. 2003; 14(8):1107-10. PMid:12821791. http://dx.doi.org/10.1097/00001756-200306110-00002.

Schupp HT, Junghöfer M, Weike AI, Hamm AO. The selective processing of briefly presented affective pictures: An ERP analysis. Psychophysiology. 2004; 41(3):441-9. PMid:15102130. http://dx.doi.org/10.1111/j.1469-8986.2004.00174.x.

Seger L. Odontologia e psicologia: uma abordagem integradora. São Paulo: Santos; 1998.

Shochat T, Gavish A, Arons E, Hadas N, Molotsky A, Lavie P, Oksenberg A. validation of the BiteStrip screener for sleep bruxism. Oral Surg Oral Med Oral Pathol Oral Radiol Endod. 2007; 104(3):e32-9. PMid:17618147. http://dx.doi.org/10.1016/j. tripleo.2007.03.009.

Taylor SE, Eisenberger NI, Saxbe D, Lehman BJ, Lieberman MD. Neural responses to emotional stimuli are associated with childhood family stress. Biol Psychiatry. 2006; 60(3):296-301. PMid:16460697. http://dx.doi.org/10.1016/j.biopsych.2005.09.027.

Weinberg A, Hajcak G. Beyond good and evil: the timecourse of neural activity elicited by specific picture content. Emotion. 2010; 10(6):767-82. PMid:21058848. http://dx.doi. org/10.1037/a0020242.

Witz K, Hinkle DE, Wiersma W, Jurs SG. Applied statistics for the behavioral sciences. J Educ Behav Stat. 1990; 15(1):84-7. http://dx.doi.org/10.2307/1164825. 